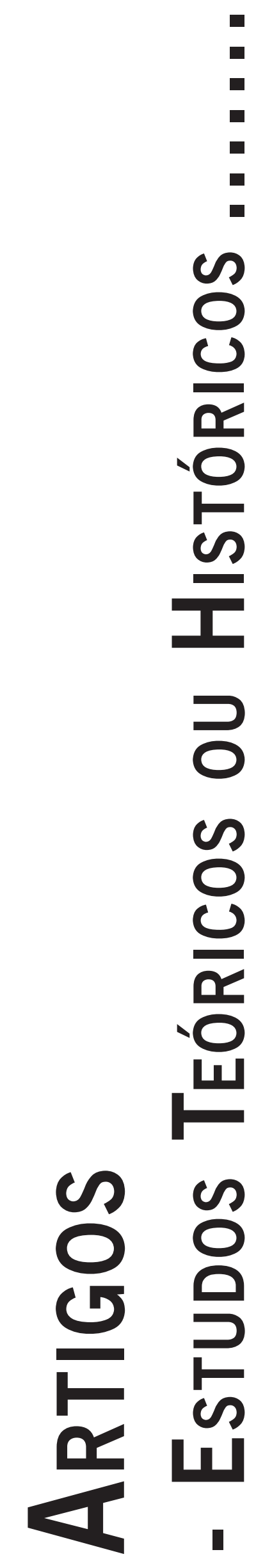




\title{
A FENOMENOLOGIA DE KÖHLER E O CONCEITO DE EXPERIÊNCIA DIRETA
}

\author{
La Fenomenología de Köhler y el Concepto de la Experiencia Directa \\ Köhler's Phenomenology and the Concept of Direct Experience
}

SÁvio Passafaro Peres

\begin{abstract}
Resumo: Um dos expoentes da Psicologia da Gestalt que mais enfatizou a necessidade do método fenomenológico na psicologia foi Köhler. Para ele, o método fenomenológico permite abordar adequadamente aquilo que ele denomina a "experiência direta", sem cometer os erros oriundos do introspeccionismo clássico. O objetivo deste artigo é detalhar o método fenomenológico de Köhler no âmbito de sua teoria da percepção. Ao fim, pretende-se mostrar que ele é central para a fundamentação da Gestalt, por servir como ferramenta para distinguir o objeto da física do objeto da experiência direta.
\end{abstract}

Palavras-chave: Intencionalidade; Fenomenologia; Wolfgang Köhler; experiência direta.

\begin{abstract}
Köhler was one of the authors of Gestalt psychology that most emphasized the need of the phenomenological method. For him, the phenomenological method allows properly approach the "direct experience" without committing the errors derived from classical introspection. The purpose of this article is to detail the phenomenological method of Köhler in his theory of perception. At the end, we intend to show that it is central to the fundaments of the Gestalt psychology. The phenomenological method serves as a tool to distinguish the direct object of external experience from the physical object.
\end{abstract}

Keywords: Intentionality; Phenomenology; Wolfgang Köhler; direct experience.

Resumen: Köhler fue uno de los autores de la psicología Gestalt que más insistieron en la necesidad del método fenomenológico. Para él, el método fenomenológico permite abordar adecuadamente la "experiencia directa" sin cometer los errores derivados de la introspección clásica. El propósito de este artículo es detallar el método fenomenológico de Köhler en su teoría de la percepción. Al final, tenemos la intención de mostrar que es fundamental para los fundamentos de la psicología de la Gestalt. El método fenomenológico sirve como una herramienta para distinguir el objeto directo de la experiencia externa del objeto físico. Palabras clave: Intencionalidad; Fenomenología; Wolfgang Köhler; experiencia directa.

\section{Introdução}

No ano de 1944, quase três décadas após o nascimento da Psicologia da Gestalt, o gestaltista David Katz (18841953) publica, na Suécia, Psicologia da Gestalt: sua natureza e sua significação (1950). Nesta obra, Katz faz uma avaliação desta escola, de seus resultados mais importantes e ainda comenta algumas de suas fontes. Dentre estas, ele põe em relevo a fenomenologia, particularmente a husserliana.

Ewald Hering, notável fisiologista, aplicou o método fenomenológico de maneira bastante proveitosa em suas investigações clássicas acerca da visão de cores. Um filósofo, Husserl (1901-1902), fez uso sistemático do método e expandiu suas aplicações. Não é exagero dizer que a compreensão da psicologia contemporânea necessita de um entendimento do método fenomenológico. (Katz, 1950, p. 18)

O motivo de iniciar este artigo com a citação de Katz não é fortuito. Ele foi não só um dos mais importantes pesquisadores da Gestalt, mas também um dos mais notórios membros da escola de Psicologia de Göttingen, tendo amplo conhecimento das concepções fundamentais da fenomenologia praticada por Husserl (1859-1938). Este fora seu professor e ocupava, ao lado do psicólogo Ellias Müller (1850-1934), orientador de Katz, uma das cadeiras da faculdade de Filosofia. Esta situação, em que psicologia e filosofia se entrelaçam, é uma marca característica da Alemanha de então. Há entre ambas as disciplinas não só uma aproximação intelectual, com vários filósofos usando declaradamente o método psicológico, como também uma aproximação institucional: é no seio das faculdades de filosofia que a nova psicologia floresce na virada para o século $\mathrm{XX}^{1}$. Como na época não havia

\footnotetext{
1 No ano de 1810 ocorreram na Alemanha importantes reformas educacionais. As faculdades de filosofia passaram a formar professores ginasiais e, em 1824, foi decretado pelo estado prussiano que a psicologia deveria ser parte de um exame estatal para avaliar os recém-formados professores ginasiais. Dada essa circunstância, coube aos filósofos ministrar a disciplina de psicologia. Isso contribuiu não só para a disseminação da psicologia na cultura alemã, como também, em um primeiro momento, para a aproximação da filosofia e psicologia. Em vista disso, não espanta que, no final do
} 
faculdades de Psicologia, quem quisesse trabalhar com esta disciplina, e mais particularmente com psicologia experimental, deveria cursar uma faculdade de Filosofia. Daí que a grande maioria dos expoentes da primeira geração de psicólogos experimentais alemães do início do século XX tinha formação em filosofia, como é o caso de Katz e Köhler.

Neste contexto não é de se espantar que Husserl, após se transferir a Göttingen em 1901, tenha sido professor de Katz e, além disso, o examinador de sua tese, publicada em 1911, Os modos de aparência da cor (1911) (Die Erscheinungsweisen der Farben). Este trabalho, que projetou Katz no ambiente intelectual alemão, recebeu não só um parecer favorável de Husserl, como também foi apontado por Köhler como um trabalho fundamental para a constituição da psicologia da Gestalt (Köhler, 1961). Particularmente importante neste trabalho é o fato de que Katz opõe-se claramente à concepção de sensações puras, abordando as cores como fenômenos, e não simplesmente como meras sensações (Köhler, 1961).

A vida e a obra de Katz se situam no centro do jogo de forças que há entre fenomenologia, psicologia experimental e Gestalt. Dada essa condição, a citação de Katz apresentada acima deve ser examinada com cuidado. Um mero passar de olhos pode induzir confusões. Logo de início, percebemos que há uma peculiaridade na maneira em que Katz entendia o método fenomenológico. Tratava-se, para ele, de um tipo de descrição "fiel" e "sem preconceitos” dos fenômenos (Katz, 1950, p. 18). Em sua opinião, Husserl não era, de maneira alguma, o inventor do método, mas apenas alguém que "fez uso sistemático do método e expandiu suas aplicações” (Katz, 1950, p. 18). Aliás, o método não era, para Katz, sequer exclusivamente filosófico, pois o âmbito de aplicação mais proveitosa era justamente a psicologia. "Em psicologia, uma atitude sem preconceitos é referida como descritiva ou fenomenológica” (Katz, 1950, p. 18). Justamente por ter um conceito amplo de fenomenologia, Katz observa que:

Köhler fez uso extensivo da fenomenologia mais do que qualquer outro psicólogo da Gestalt. As suas ocasionais referências à "mesa experienciada" ou uma “cadeira experienciada” devem ser compreendidas à luz do método observacional. Não é necessário dizer que ele não entende por isso a cadeira física ou a mesa física, mas refere àqueles objetos tais como eles aparecem fenomenologicamente. Por vezes ele coloca mais peso nos dados fornecidos por observadores "näive" do que nos produzidos por observadores profissionais. (Katz, 1950, p. 19)

século XIX e início do século XX, algumas cadeiras de filosofia passaram a ser ocupadas por psicólogos experimentais. Contudo, isso acabou gerando uma reação negativa por parte dos filósofos puros, culminando em uma crise institucional, cujo ápice foi o ano de 1913, quando os filósofos puros se associaram para impedir a ocupação de cadeiras de filosofia por psicólogos experimentais (Araújo, 2013).
O que deve ser assinalado para o argumento que será desenvolvido neste artigo são os conceitos de observador näive e a distinção entre objetos experienciados, tais como eles aparecem fenomenologicamente, por um lado, e objetos físicos, por outro. Esta distinção joga um papel central para o projeto da psicologia da Gestalt, já que ela está relacionada com a correta compreensão da noção de "experiência direta”, tida por Köhler como o domínio fundamental da psicologia. Ou seja, a experiência direta está vinculada com os dados produzidos por observadores ingênuos. O detalhamento desse vínculo permite especificar conceitualmente aquilo que Köhler entende por fenomenologia. Não é nosso objetivo, é preciso salientar, abordar o tema da experiência direta, tal como hoje em dia é abordada por psicólogos e pesquisadores que se valem das ideias da psicologia da Gestalt. Embora seja uma tarefa importante, nosso objetivo é outro, consiste em elucidar as posições filosóficas de Köhler sobre o assunto.

\section{Alguns elementos históricos da Psicologia da Ges- talt: a herança brentaniana}

Em 1947, Köhler, já residindo nos Estados Unidos, publica a sua famosa Psicologia da Gestalt. Não é exagero afirmar que se trata de uma das obras mais influentes da Gestalt, não só pelo sucesso editorial, constituindo uma das mais compactas introduções a Gestalt ${ }^{2}$, mas também porque nela Köhler opera uma incisiva crítica a dois modelos de psicologia influentes em seu tempo, o introspeccionismo clássico, defendido por Edward Titchener (1867-1927), e o behaviorismo clássico de John B. Watson (1878-1958). Para isso, Köhler se empenha em clarificar o conceito de experiência direta, mostrando que o erro do introspeccionismo clássico reside em sua má compreensão, enquanto o behaviorismo, contrapondo-se, com razão, a essa má compreensão, acaba por rechaçar por completo o conceito de experiência direta. Contudo, a experiência direta constitui não só um autêntico domí-

\footnotetext{
O texto é uma edição revisada que saiu em 1947 de uma obra originalmente escrita de 1929. Por ser uma edição revisada é plausível acreditar que Köhler esteja em concordância com o conteúdo do texto. Esse ponto é importante, pois em uma obra de 1938, The Place of Value in a World of Facts, Köhler dá um tratamento bem mais extenso à relação entre o objeto fenomenológico e o objeto físico. Por que então, usar a obra de 1947 como corpus de análise? A melhor resposta é que isso se dá por cuidados metodológicos, para respeitar o desenvolvimento genético evolutivo do pensamento do autor. Nada garante, a princípio, que Köhler pense em 1947 o mesmo que pensava em 1938. Assim como nada garante, a princípio, que ele mantenha o mesmo pensamento nos anos subsequentes. Por exemplo, em um artigo de 1944, "Fato e Valor", Köhler afirma que, devido a uma conversa com Ernest Nagel e C. G. Hempel, ele acabou por rever determinadas posições que ele, um ano antes, defendia (1944/1978b, p. 109). Mas se há uma evolução no pensamento de um autor, há também certos traços que se mantém. Por essa razão, embora eu empregue como corpus central de análise a obra Psicologia da Gestalt (1929/1968), irei mostrar, por meio de citações e indicações, onde as mesmas ideias podem se encontrar em outras obras de Köhler.
} 
nio de investigação da psicologia, como também é a condição de possibilidade epistemológica não só de qualquer psicologia, mas também da física.

Para Köhler, introspeccionismo clássico e behaviorismo são metodologicamente e epistemologicamente ingênuos. $\mathrm{O}$ primeiro compreende o conceito de experiência direta pelo viés de preconceitos derivados de uma concepção mecânica da natureza, oriunda da fisiologia do século XIX (1929/1968, p. 62-80). O segundo consiste basicamente em uma tentativa atrapalhada de imitar o método das ciências naturais, mais particularmente o da física (1929/1968, p. 23). Enquanto o primeiro crê que o dado intuitivo básico são as sensações, vinculadas mecanicamente com estímulos locais, o segundo crê que o dado básico é "o mundo físico observável”. Ambos os métodos não apenas partem de pressupostos equivocados, como também assumem um pressuposto comum: a visão mecânica da natureza (Köhler, 1929/1968, p. 62-80), visão essa que, embora tenha sido superada na física já no início do século XX, continua a modelar, em particular na época em que Köhler escrevera o texto, o pensamento científico dos psicólogos. Estes, ignorantes da física do século XX, continuavam a se inspirar na mecânica clássica ao confeccionar suas teorias psicológicas.

Em certo sentido, é possível afirmar que a corrente psicológica da Gestalt tem uma de suas origens em Brentano, intermediada por seus alunos, especialmente Stumpf (1936-1948), fundador do instituto de Berlim, e Ehrenfels (1856-1932), cuja obra mais influente é Über Gestaltqualitäten (cf. Smith, 1994). Por essa razão, não é de se admirar que várias das posições defendidas por Köhler se aproximam em muitos pontos de Brentano de Psicologia do ponto de vista empírico (1874) dado que, para ambos:

1) Há a distinção entre objeto da experiência direta (percepto, objeto fenomênico) e coisa física. (Köhler, 1966/1971, p. 87). Para Brentano, tanto quanto para Köhler, o objeto físico tem uma existência "transfenomênica”. (Köhler, 1938, p. 104; Brentano, 1874, p. 11). Essa distinção é válida até para nossos corpos. A esse respeito, Köhler afirma que "o corpo fenomênico enquanto percepto tem que ser claramente distinguido do organismo físico". (1938, p. 65)

2) A relação da experiência com o objeto experienciado é intrínseca à própria experiência. Para Köhler (1929/1968, p. 19), o objeto experienciado é parte da experiência consciente (1929/1968, p. 19). Para Brentano (1874, p. 115), o fenômeno psíquico contém uma objetividade imanente. Brentano distingue entre ato e objeto imanente, os quais são interdependentes, ou seja, um não pode existir sem o outro. Köhler distingue um aspecto subjetivo do aspecto objetivo da experiência (Köhler, 1929/1968, p. 18).

3) A própria experiência direta, bem como o objeto imediato da experiência, é um produto de processos fisiológicos cerebrais (Brentano, 1974; Köhler, 1960/1978a, p. 129-147; 1929/1968, p. 20,22).
Contudo, há em Köhler várias diferenças importantes com relação a Brentano. Cito duas que são particularmente importantes para o argumento deste artigo. A primeira é que, para Köhler, o objeto tal como percebido entra no domínio de investigação da psicologia, enquanto, para Brentano, apenas os atos (o que ele denomina de “fenômenos psíquicos”) entram no domínio da psicologia. A segunda diferença, que em certo sentido deriva da primeira, reside no tratamento dado por Köhler ao objeto tal qual é dado na experiência. A “objetividade” que é diretamente dada no ato psíquico não é identificada, como em Brentano, ao conteúdo de sensações (1874, p. 115). Para Köhler, o que é percebido na percepção externa é um percepto, o qual não pode ser reduzido a uma coleção de sensações, nem ao conteúdo sensorial da percepção exterior. Esta irredutibilidade do percepto ao conteúdo sensorial é uma concepção que, segundo Köhler, a escola da Gestalt tirou de Ehrenfels (1890), aperfeiçoando-a (Köhler, 1961, p. 2).

\section{As propriedades do percepto e as propriedades do mundo físico}

Um dos pontos de partida da exposição de Köhler é tomar a física como exemplo de ciência. O mundo, tal como aparece na experiência perceptiva, não corresponde ao mundo tal qual é concebido pela física. Sejam quais forem as propriedades do mundo da física, elas não são as mesmas do mundo tal como experienciado na vida cotidiana e na experiência direta. O mundo da experiência direta muitas vezes possui propriedades contraditórias. "O mundo do homem é algo de confuso e revela seu caráter subjetivo em qualquer exame crítico de suas propriedades, no mundo dos físicos não são toleradas quaisquer confusões ou contradições.” (Köhler, 1929/1968, p. 10). A vara imersa sobre a água parece quebrada, o Sol é vermelho quando se põe e amarelo quando atinge o zênite. Os exemplos abundam, podemos lembrar aqui do experimento que Locke oferece no capítulo VIII do segundo livro do Ensaio sobre o Entendimento Humano (1689/1975, p. 146). Se uma pessoa esfria uma mão e aquece a outra e logo na sequência submerge ambas as mãos em um recipiente com água, a água parecerá quente a uma das mãos e fria à outra; ainda assim, a temperatura física da água é a mesma.

Segundo Köhler, a história da física revela de modo inequívoco que seu desenvolvimento se deu de maneira a se afastar cada vez mais da experiência direta, já que esta possui muitas propriedades contraditórias. Houve, devido a essas propriedades contraditórias, uma desconfiança crescente em relação ao mundo tal como aparece e o impulso de descobrir o mundo tal como ele é. E há alguns séculos atrás, a física e biologia começaram a "solapar a confiança singela dos seres humanos no sentido de considerar este mundo (n.d.r: o mundo da experiência 
direta) como a realidade” (Köhler, 1929/1968, p. 10). Já a experiência de Locke, citada anteriormente, deixa claro que as propriedades do objeto experienciado são dependentes do sujeito. O projeto da física consiste não em descobrir as características dos objetos tais como aparecem, mas sim as propriedades do mundo físico, as quais devem ser independentes da subjetividade daquele que conhece.

\section{Alguns problemas históricos da relação entre 0 mundo da experiência direta e o mundo físico}

É possível afirmar que essa distinção entre o dado na experiência e um algo que se encontra por trás da aparência é um tema recorrente em toda a história da filosofia, em diferentes versões (Rockmore, 2011, p. 1-16). Inicialmente, podemos lembrar a distinção clássica entre aparência e essência formulada por Platão em seu mito da caverna (Platão, IV a.C./1997, p. 225-256). Podemos também lembrar a distinção aristotélica entre substância e acidente (Aristóteles, IV a.C./2009, p. 213-217).

Esta última distinção encontra-se reformulada em Descartes, para quem a polaridade se encontra na relação representação subjetiva (cogitatum) x natureza física (Hatfield, 2003, p. 237-280). Descartes, como se sabe, reformula o conceito aristotélico de substância. Ao contrário de Aristóteles, para quem havia uma enorme variedade de substâncias, Descartes (1641/1975) assume a existência de apenas de três: Deus, o espírito humano (res cogitans) e o mundo (res extensae). Esta última, caracterizada pela extensão, carrega em si a possibilidade de ser descrita geometricamente. Em Descartes, o projeto de matematização do universo ganha uma de suas formas mais poderosas: investigar o mundo é investigar a res extensae pelo método matemático. A dificuldade que advém da distinção entre as duas substâncias reside, em primeiro lugar, na "comunicação" entre elas.

A distinção operada por Descartes está na raiz da virada epistemológica da filosofia. Se o problema antes era o Ser e a disciplina básica da filosofia era a ontologia, com Descartes e a partir dele o problema que irá se instaurar e irá ocupar o centro gravitacional da filosofia até o fim do século XIX será o problema epistemológico (Rockmore, 2011, p. 1-16). Um dos problemas mais abordados diz respeito à possibilidade de acesso cognitivo ao mundo exterior ao sujeito. Descartes procura legitimar a possibilidade epistêmica de se conhecer o mundo exterior fundamentando-se na bondade de Deus. Locke aceita a distinção operada por Descartes entre a consciência e o mundo exterior, mas rejeita a solução cartesiana procurando uma nova solução ao problema do acesso da consciência ao mundo exterior, com sua doutrina das qualidades primárias e secundárias (McCann, 2006, p. 63). Köhler, como antes já havia feito Brentano, não mais aceita a distinção operada por Locke entre qualidades primárias e secundárias.
Finalmente, porém, as qualidades primárias da realidade singela mostraram-se tão subjetivas quanto as secundárias: a forma, o peso e o movimento das coisas tiveram de ser interpretados da mesma maneira que as cores e os sons; também eles dependiam do organismo que os experimentava e eram meros resultados finais de complicados processos no seu âmago. (Köhler, 1929/1968, p. 11)

Dadas as propriedades contraditórias e problemáticas dos objetos tais como experienciados, “(...) a ciência teve que construir um mundo objetivo e independente, de coisas físicas, espaço físico, tempo físico e movimento físico, e de afirmar que tal mundo não aparece, de modo algum, na experiência direta.” (Köhler, 1929/1968, p. 11).

Köhler afirma que a experiência consciente de ver um objeto (por exemplo, uma cadeira) é "produzida” (Köhler, 1929/1968, p. 20) por processos no organismo; em outras ocasiões, ele afirma que é o percepto é "efeito" de processos que ocorrem no organismo. (Köhler, 1929/1968, p. 18). Enquanto a cadeira e suas propriedades percebidas são dependentes de processos fisiológicos cerebrais, a própria cadeira física, a qual não é de modo algum a cadeira da experiência, é transcendente e independente da cadeira percebida. A cadeira física não pode ser vista nem experienciada diretamente de maneira alguma.

Os processos psíquicos conscientes são dependentes de processos no organismo. Contudo, é possível conceber várias formas acerca do modo como se dá essa dependência. E é justamente o modo como Köhler a estabelece que merece nossa atenção. Ele não entende que o organismo seja "causa" dos processos psíquicos no sentido natural do termo, na qual toda ação possui uma reação, pois esta posição entraria em choque com a tese física da conservação de energia. Em seu artigo "O problema mente-corpo”, de 1960, Köhler é mais preciso sobre o significado da dependência dos processos psíquicos com relação aos processos físicos que ocorrem no interior do organismo. Ele rejeita: a) toda forma de dualismo das substâncias, em que se considera que há uma substância mental e uma substância física; b) o interacionismo, em que duas substâncias heterogêneas interagem causalmente; c) o vitalismo (1960/1978a, p. 145; 1929/1968, p. 80), em que as leis físicas não são válidas para organismos vivos. Contra essas posições, ele defende um tipo particular de emergentismo, em que alguns processos físicos (processos cerebrais) são "acompanhados" por processos psíquicos (1960/1978a, p. 145). O que especifica o tipo particular de emergentismo da Gestalt é a tese do isomorfismo, pela qual se afirma que "as características estruturais dos processos cerebrais e dos eventos fenomenológicos são as mesmas.” (1960/1978a, p. 145). Isso reforça a necessidade de uma fenomenologia, pois esta pode oferecer descrições adequadas dos eventos fenomenológicos, as quais cumprem um importante papel para investigação da relação mente-corpo. 


\section{0 objeto experienciado é uma experiência}

A experiência consciente, uma vez que é causada por processos cerebrais, é dependente do mundo físico. Já o mundo físico não é dependente do mundo subjetivo. Dito isto, podemos apresentar a seguinte estrutura argumentativa apresentada por Köhler (1929/1968, p. 19-21):

1) A experiência perceptiva é causada por processos cerebrais.

2) A experiência é um todo composto de partes.

3) As partes da experiência são também experiências.

4) O objeto percebido (pecepto) é uma parte da experiência.

5) Logo, o objeto percebido é uma experiência.

Köhler, desta forma, usa de maneira intercambiável os termos "objeto da experiência" e "experiência objetiva”. Isso conduz a maneiras de falar que, no mínimo, causam certa estranheza. Quem observa um objeto observa, portanto, uma experiência objetiva (1929/1968, p. 20). Com isso, Köhler opera uma expansão do significado do termo "objeto", o qual pode se referir tanto a um objeto fenomênico (percepto ou experiência objetiva), quanto a um objeto físico.

\section{Uma possível objeção: subjetivismo}

No momento em que Köhler afirma que o objeto que percebemos é uma experiência objetiva, ele tem consciência de que está correndo o risco de "psicologizar" todo objeto que não seja o objeto físico. Por essa razão, é de se esperar a seguinte objeção à teoria de Köhler, a qual se fundamentaria no seguinte raciocínio:

a) Toda experiência é consciente.

b) Todas as partes da experiência são também experiência.

c) O objeto experienciado é uma parte da experiência.

d) Logo, o objeto experienciado é subjetivo.

Esta conclusão parece indicar que Köhler subscreve uma forma de subjetivismo solipsista. O que é dado na percepção não é nem o mundo físico, nem dados de sensação, nem conteúdos sensoriais, mas sim perceptos. Mas o que é um percepto? Não se trata de algo mental e privado? Köhler, para escapar desta acusação, opera uma série de distinções conceituais bastante engenhosas:

1) Distingue duas formas de se conceber a oposição conceitual subjetivo-objetivo. (Köhler, 1929/1968, p. 18).

2) Distingue experiência direta (imediata) da experiência indireta (mediata). (Köhler, 1929/1968, p. 20).

3) Distingue dois mundos, vinculando cada um deles a uma forma de experiência:

a) O mundo da experiência direta (Köhler, 1929/1968, p. 10); também designado por "mundo cotidiano", "mundo em que vivemos" (Köhler, 1929/1968, p. 20), "mundo tal qual descobrimos, de maneira simples e desprovida de crítica" (Köhler, 1929/1968, p. 9), mundo da "atitude natural" (Köhler, 1929/1968, p. 9) e ainda "mundo fenomenológico". (1960/1978a, p. 134)

b) O mundo da experiência indireta; também designado por mundo da física, ou para usar um termo cunhado por Köhler, em 1938, um mundo "transfenomênico". (Köhler, 1938).

A forma como essas três distinções estão articuladas será exposta nas seções subsequentes.

\section{0 duplo significado da oposição "subjetivo e obje- tivo"}

Como pudemos notar, a acusação de subjetivismo se fundamenta na premissa de que "toda experiência é subjetiva”. Mas essa premissa não pode ser simplesmente aceita. Como o termo subjetivo pode ser empregado em dois sentidos, é preciso, antes de simplesmente afirmar que a experiência é subjetiva, saber em que sentido o termo está sendo empregado. Há, segundo Köhler, dois sentidos nos quais se diz que a experiência é subjetiva:

1) Uma experiência é subjetiva na medida em que é resultante de processos fisiológicos que ocorrem no organismo, em especial de processos cerebrais. Em oposição, apenas o mundo físico é objetivo. O próprio organismo, como faz parte do mundo físico, é objetivo. De acordo com esse sentido, tudo o que é ou está na consciência é subjetivo, assim como qualquer objeto de que temos consciência imediata. Segundo Köhler, tal conceito de subjetivo só faz sentido em contraposição ao conceito de objetivo, o qual serve para designar o objeto físico, ontologicamente independente da subjetividade. Sem uma noção mínima de mundo físico "transfenomênico", tal conceito de subjetivo não faria sentido.

2) Uma experiência é subjetiva na medida em que ela se manifesta como subjetiva. Ex.: um pressentimento, um sentimento, uma fantasia, uma obsessão, um desejo de comer morangos. O polo oposto desta acepção é o que aparece como objetivo. Ex: a cadeira que eu percebo, a caneta que sinto com meus dedos e assim por diante. (Köhler, 1929/1968, p. 21). Tais objetos não se apresentam como algo privado e pessoal, tais como meus sentimentos e minhas fantasias. Consequentemente, tais objetos, dados na experiência direta, são "experiências objetivas".

A fim de facilitar o emprego dos termos, passemos a distinguir entre "geneticamente subjetivo" e "fenomenologicamente subjetivo".

"Geneticamente subjetivo" é predicado de toda e qualquer experiência, uma vez que toda experiência é resultado de processos no organismo físico. "Fenomenologicamente subjetivo" é predicado de determinadas experiências ou de certas partes de uma experi- 
ência. Assim, temos a seguinte situação. Toda experiência é geneticamente subjetiva. Entretanto, ela pode ser "fenomenologicamente subjetiva" ou "fenomenologicamente objetiva”. É sobre esta última que agora iremos nos ater.

\section{A experiência objetiva}

Para introduzir o conceito de experiência objetiva, Köhler usa como exemplo o tempo de sua infância. Quando criança, ele tomava aquilo que era dado diretamente como existindo independentemente de suas experiências. "Em meu mundo original, inúmeras variedades de experiência mostraram-se inteiramente objetivas, isto é, existindo ou ocorrendo externa e independentemente." (1929/1968, p. 18). O que Köhler procura mostrar é que o conceito de experiência objetiva só possui significado na medida em que o sujeito compreende que há um mundo físico por trás do mundo da experiência direta. Ao tomar contato com o mundo físico (átomos, energia, campos eletromagnéticos), o mundo que tínhamos como mundo real passa a ser tomado como mundo fenomênico e o mundo físico passa a ser agora o mundo real. O realismo ingênuo consiste em tomar o mundo tal como dado na experiência direta objetiva como o mundo real. (1960/1978a, p. 134). Se Köhler é realista, o é no sentido de aceitar a tese de que há uma realidade e que essa é uma realidade física transfenomênica (Engelmann, 2002, p. 4,10).

Se eu observo uma cadeira, o que ocorre é que observo, segundo Köhler, uma experiência objetiva. Por mais estranho que seja, Köhler é claro: quem observa algo diretamente, observa uma experiência ou parte de uma experiência. Tal maneira de compreender as coisas pode levar a consequências aparentemente absurdas, às quais podem ser expressas nas seguintes perguntas:

1) Como é possível que um objeto que vejo como estando longe de mim seja uma experiência minha, produzida por mim?

2) Como é possível que o objeto fenomenológico seja dotado de validade intersubjetiva? Se o que percebo é algo que existe apenas na minha experiência e, portanto, só existe em mim, como é possível que um mesmo algo seja visto e compartilhado por outros sujeitos?

Respondo aqui a primeira pergunta e deixarei para o final do artigo uma sugestão de resposta para a segunda pergunta, a qual depende da tese do isomorfismo. A solução de Köhler ao primeiro problema consiste em observar que, quando eu afirmo que o objeto aparece como estando distante de meu corpo, o que se deve levar em consideração é que, no caso, o termo "meu corpo" refere-se a um objeto fenomênico, separado por um espaço fenomênico, de outro objeto fenomênico (percepto). Mas o espaço fenomênico, o corpo fenomênico e o objeto diretamente percebido são produtos do organismo físico e devem, respectivamente, ser distinguidos do espaço físi- co, do organismo físico e do objeto físico correspondente. "O que chamamos de self é apenas um percepto mais acessível... Quando lidamos com a percepção, devemos distinguir com precisão entre o eu, enquanto perceto e o organismo físico em questão.” (1966/1971, p. 83).

Köhler não dá margens a más interpretações, é exatamente este o sentido: "Além disso, a única maneira de que disponho para investigar as realidades físicas consiste em observar experiências objetivas (observing objetive experience) e delas tirar as conclusões adequadas" (1929/1968, p. 20). Ou seja, o que o físico observa ao olhar no galvanômetro não é um objeto físico, mas algo que é parte de seu campo visual, tanto quanto o fio metálico que ele vê. Tanto o galvanômetro quanto fio que ele vê manifestam eles mesmos como partes da experiência objetiva (manifest themselves as parts of objective experience) (Köhler, 1929/1968, p. 21).

Ora, uma das conclusões que se pode tirar deste esquema apresentado por Köhler é que toda "experiência de algo" é compreendida como uma relação entre dois aspectos de uma mesma experiência englobante. No momento em que ele afirma coisas como "observo uma experiência objetiva”; (1929/1968, p. 20) "o aparelho se manifesta como parte do campo visual” (Köhler, 1929/1968, p. 21), "Estou ciente da presença da mistura (n.d.r: vinagre) graças a certas experiências objetivas que tenho diante de mim.” (1929/1968, p. 21), fica claro que as experiências objetivas são "observadas", estão "diante de mim”, fazem parte integrante de "meu campo visual". O ato de observar é uma experiência subjetiva, enquanto o observado é uma experiência objetiva.

Para Köhler, não compreender as coisas desta forma é ingenuidade, a mesma ingenuidade que ele tinha na infância, época em que ele não havia descoberto a experiência direta, já que a condição de possibilidade de concebê-la é adquirindo conhecimentos sobre o mundo da física. Em nossa vida cotidiana, observarmos a todo instante apenas nossas experiências, mas, devido à nossa inclinação natural ao realismo ingênuo, tomamos irrefletidamente o percepto como realidade (1960/1978a, p. 134; 1929/1968, p. 10).

\section{Behaviorismo e experiência direta}

Como pudemos observar logo acima, para Köhler, o que o homem percebe não é o mundo físico, senão um efeito produzido por processos que ocorrem no interior do organismo. Uma das consequências teóricas desta tese é que aquele que descreve o mundo tal como percebido não está descrevendo o mundo físico. Neste sentido, a física não é uma ciência que se propõe a descrever ou explicar o mundo tal como percebido. Em outros termos, a física não busca conhecer os fenômenos observáveis, pois os fenômenos são dependentes do organismo, podendo variar conforme variam os organismos. Se fenômeno é o 
que aparece tal como aparece, é claro que a física não é uma ciência de fenômenos. Não obstante, os fenômenos constituem a base necessária a partir da qual compreendemos o mundo físico. Apenas o homem ingênuo acredita que descrever o mundo tal como ele percebe significa adotar a assim chamada "a atitude objetiva do físico".

É justamente aí que Köhler se prepara para atacar a ingenuidade dos behavioristas clássicos. Estes, justamente por quererem imitar os procedimentos adotados na física, embora sem conhecê-la e sem uma reflexão epistemológica adequada sobre a mesma, acabam imitando não a física, mas uma caricatura da mesma. Por serem incapazes de compreender que há uma experiência fenomenologicamente objetiva, embora geneticamente subjetiva, procuram excluir toda e qualquer experiência do domínio da psicologia. Acreditam, desta forma, que estão investigando o mundo objetivo, o mesmo de que falam os físicos. Raciocinam os behavioristas clássicos: se o objeto de estudo dos físicos é o mundo exterior observável, logo o objeto de estudo da psicologia também deve ser o mundo exterior observável e não o "mundo interior subjetivo". Guiado por esta presunção, o behaviorista crê que o autêntico objeto da psicologia é o comportamento observável e não a experiência direta. No entanto, o behaviorista não percebe que:

1) Só pode descrever o comportamento observável se ele tem uma experiência perceptiva do comportamento do animal que ele pretende observar.

2) O que é dado na percepção não é "realidade" exterior, física, ontologicamente independente da mente, senão o efeito de estímulos físicos sobre o organismo.

Ao fazer isso, o behaviorismo comete dois erros, frutos da ingenuidade. Em primeiro lugar, ele nega que a psicologia seja uma ciência da experiência direta, mas emprega a experiência direta como ferramenta epistêmica. (Köhler, 1929/1968, p. 23). Em segundo lugar, ele crê que, ao descrever o que é dado na experiência direta, ele está investigando o mundo real, identificando-o com o mundo físico. Portanto, o erro do behaviorismo é "dar a impressão de que o mundo físico e fisiológico, em si mesmos, são diretamente conhecidos e que, no caso deles, partidários do behaviorismo, o conhecimento nada tem a ver com a experiência direta”33 (1929/1968, p. 21).

\section{Sujeito e objeto como partes de um mesmo sis- tema}

Uma das razões alegadas pelos behavioristas para negar que a psicologia possa ser uma ciência da experiência reside em um famoso argumento, segundo o qual apenas

\footnotetext{
Em 1960, em função do desenvolvimento do comportamentalismo, Köhler reconhece que "Os modernos psicólogos do comportamento não mais sustentam a ideia de que o mundo fenomenológico foi inventado pelos metafísicos.” (1960/1978a, p. 131).
}

o próprio sujeito tem acesso direto às suas experiências. As experiências são privadas e cada pessoa tem acesso apenas às suas próprias. Como consequência, quem quer estudar a experiência deve observar suas próprias experiências. Mas como isso é possível? Afinal, argumenta o behaviorista, "A introspecção e seus objetos são fatos que se situam dentro do mesmo sistema, sendo diminuta a possibilidade de que a primeira não afete os segundos." (Köhler, 1929/1968, p. 13). No momento em que buscamos apreender reflexivamente a tristeza que vivíamos, a tristeza perde sua força e é modificada. Ou seja, a experiência, tal como originariamente vivida, altera-se em virtude do ato reflexivo.

A objeção levantada pelos behavioristas sustenta-se em alguns pressupostos assumidos (1929/1968, p. 23): a) Considerar que é possível observar, com o uso dos sentidos, o mundo físico ou qualquer sistema físico. b) Supor que observar experiências implica em introspecção. c) Supor que, na física, o observador se encontra fora do sistema que observa. d) supor que fazer parte do sistema que se observa é fator que impede o conhecimento deste sistema.

Contra tais objeções, é preciso observar que o físico não tem outro ponto de partida possível e outra base possível senão a experiência direta (1929/1968, p. 23; 1960/1978a, p. 131). Ora, o que é dado na experiência direta do físico não é um objeto físico, mas um objeto fenomênico, o qual nada mais é do que o efeito de processos no interior de seu organismo, assim como o ato de observar a experiência objetiva também o é. Em suma, sujeito que percebe e objeto percebido são produtos de um mesmo sistema, a saber, o organismo. Mas isto não constitui, ao ver de Köhler, um grave problema, pois na física algo análogo ocorre. "De fato, no caso da observação física, a situação é semelhante: o material a ser observado e o processo de observação pertencem ao mesmo sistema”. (Köhler, 1929/1968, p. 23). Daí que o físico não se encontra em melhor situação do que o psicólogo.

Mas se a física não busca descrever o mundo tal qual aparece, o que dizer então de ciências que se pretendem explicitamente descritivas, como a botânica e a anatomia? Levando às últimas consequências o que Köhler afirma, devemos considerar que elas, tanto quanto o behaviorismo, não são ciências aptas a descrever o mundo físico, senão ciências que descrevem experiências objetivas. Em suma, se cada experiência objetiva, por definição, é apenas efeito de processos fisiológicos, então todas as ciências observacionais nada mais são do que ciências que descrevem efeitos subjetivos de processos que ocorrem no organismo, mas não o próprio mundo físico. Mas é aceitável afirmar que todas as ciências descritivas e observacionais estão destinadas a descrever fatos mentais e não o mundo físico?

Embora, a princípio, soe inverossímil, parece não restar alternativa a Köhler senão optar pela afirmativa. As ciências descritivas têm por domínio objetos que, embo- 
ra geneticamente subjetivos, são fenomenologicamente objetivos. Mas tal situação é aceitável? Um anatomista estaria disposto a aceitar que o que ele descreve não é o mundo em si, mas uma experiência (mesmo que objetiva)? Não se trata de uma forma disfarçada de "subjetivizar" a realidade? Não se trata apenas de uma nova versão da teoria brentaniana do objeto imanente? Köhler não defende que todo objeto percebido e experienciado é apenas um objeto mental e não existe realmente? A resposta de Köhler, como nós já havíamos indicado, consiste em vincular a experiência direta objetiva ao mundo cotidiano, vinculando este último ao mundo físico por meio da tese do isomorfismo.

\section{Conclusão: o mundo cotidiano como mundo da experiência direta objetiva}

Vimos que, levando às últimas consequências, o pensamento de Köhler aparentemente conduz a um problema. Se o objeto visto não é um objeto real, mas apenas uma experiência objetiva, Köhler então não poderia ser considerado um psicologista? Afinal, não há em Köhler uma estranha mistura de realismo fisicista com um subjetivismo solipsista? Não defende Köhler a tese de que o sujeito tem acesso direto apenas às suas próprias experiências? Isso não implicaria na redução das leis lógicas a leis naturais do pensar? Não é isso uma forma de psicologismo (Husserl, 1900/1968)? É interessante observar que os psicólogos da Gestalt estavam informados de tais possíveis objeções e buscaram se defender. Koffka (1935/1975, p. 579), por exemplo, defende-se ao observar que a concepção de Husserl de psicologia era demasiadamente limitada, na medida em que este considera que as “relações psicológicas são fatuais e externas". E Köhler (1938, p. 45-49) faz uma longa discussão sobre o tema, na qual ele procura mostrar as diferenças entre suas posições e a de Husserl. Uma dessas diferenças é que Köhler (1944/1978b, p. 116) não vê razão para a efetuação da epoché, isto é, o procedimento metodológico empregado por Husserl (1913/1950), que consiste na suspensão da tese de um mundo transcendente e independente da consciência. Por razões sistemáticas, Köhler não poderia aceitar, pois, como vimos, ele defende que as experiências são resultados de um mundo não fenomenológico, dado na experiência mediata, a saber, o mundo físico. Ao assumir essa posição, a fenomenologia da Gestalt assume traços peculiares.

Toda ciência que pretende descrever o mundo observável, dentro da perspectiva da Gestalt, nada mais é do que uma ciência que descreve experiências objetivas. Parece difícil senão impossível sustentar a tese de que as experiências objetivas não pertencem ao domínio de investigação da psicologia, já que a fenomenologia da Gestalt trabalha a serviço da psicologia. Mas isso não reduziria uma imensa área do saber à psicologia? Qual a saída de Köhler? Sua estratégia é interpretar o conceito de experiência objetiva a partir do conceito de mundo $d a$ experiência direta, o qual não é outro que o mundo cotidiano. A análise da experiência direta objetiva torna-se, portanto, análise o mundo da vida cotidiana. Este não é nada de subjetivo, pois é, do ponto de vista fenomenológico, objetivo. Ou seja, embora o mundo da física seja ontologicamente independente, é possível falar em outro mundo, ontologicamente dependente do sujeito. Mas o fato de ele ser ontologicamente dependente do sujeito não implica que ele seja um mundo de meras aparências. "Quando falo a respeito de uma cadeira, refiro-me à cadeira de minha vida cotidiana e não a um fenômeno subjetivo”. (Köhler, 1929/1968, p. 20). Köhler acrescenta que, em nossa atitude natural, somos todos realistas ingênuos, pois tomamos os perceptos como existindo independente de nós. (1960/1978a, p. 134)

Há, por assim dizer, dois mundos, o da física e o da vida cotidiana. $\mathrm{O}$ mundo da experiência direta, embora dependente do organismo, não deixa de ser objetivo e de ter uma consistência própria. Ele não é algo que está sob a ação de minha vontade ou uma criação ex nihilo de meu organismo. Como consequência, Köhler acaba por introduzir uma espécie de dupla ontologia: o mundo da experiência imediata e o mundo da experiência mediata. A cadeira, tomada como "experiência objetiva", é também “algo externo, sólido, estável e pesado”. (1929/1968, p. 18) E esta mesma cadeira deve ser distinguida da cadeira física.

Dada essa situação, as experiências objetivas, vinculando entre si, constituem o mundo da vida. Mas é preciso observar que o mundo da vida cotidiana é, por assim dizer, imanente, no sentido de que tanto o processo de ver um objeto quanto o objeto percebido são produções do organismo. Mas se assim é, podemos perguntar: o que garante a validade intersubjetiva dos perceptos? Como eles podem ser simultaneamente privados e intersubjetivamente acessíveis, de modo a legitimar a afirmação de que eles fazem parte de um "mundo"? É esse "mundo" privado ou não? Em Psicologia da Gestalt (1929/1960), Köhler não entra em detalhes sobre esse ponto, se limitando a afirmar que isso não é um problema na física e que dois pesquisadores entram facilmente em acordo quanto ao valor marcado por um ponteiro de um galvanômetro (Köhler, 1929/1968, p. 23). Ao que parece, Köhler aceita que o percepto possui, em determinada medida, validade intersubjetiva. Mas como é possível essa validade se os perceptos são produções do organismo? Não seria de se supor que cada pessoa tenha acesso apenas aos seus próprios perceptos? Não seria estranho que dois organismos produzam o "mesmo" percepto? Ao que parece, o caminho da solução é considerar que, embora duas pessoas nunca vejam exatamente o mesmo percepto, para fins práticos é possível afirmar que duas pessoas podem ver o "mesmo" percepto ou ter a "mesma" experiência objetiva. Köhler parece sugerir a seguinte fundamentação para 
isso. A objetividade do mundo fenomenológico cotidiano, do mundo em que vivemos, é derivada da objetividade do mundo físico. A condição de possibilidade da experiência da objetividade se encontra na objetividade do próprio organismo. É o organismo, em sua dinâmica com a globalidade dos estímulos recebidos, que gera todas as experiências, tanto as fenomenologicamente objetivas quanto as fenomenologicamente subjetivas. A experiência fenomenologicamente objetiva tem como seu correlato mais imediato não o objeto físico, mas um processo cerebral, com o qual ela compartilha características estruturais, segundo a tese do isomorfismo. A objetividade das estruturas cerebrais garantiria, se é válida a tese do isomorfismo, a objetividade dos perceptos. Com essa tese a Gestalt pode vincular pesquisas fenomenológicas com pesquisas fisiológicas, extrapolando o domínio da fenomenologia em estrito senso. Assim, os psicólogos da Gestalt usam a fenomenologia em duas direções. As descrições fenomenológicas possuem valor por si só, mas também servem como meio de acesso ao mundo não fenomenológico, em particular, os processos cerebrais. Essa posição ainda hoje se mantém, por exemplo, no recente artigo Gestalt Factors in the visual neurosciences, Spillmann and Ehrenstein defendem que a Gestalt foi "mais do que uma simples fenomenologia” (2003, p. 1573), pois foi uma das primeiras abordagens sistemáticas "para inferir processos cerebrais a partir de perceptos." (2003, p. 1573).

Um dos aspectos interessantes do pensamento de Köhler, que o aproxima de várias outras correntes de fenomenologia, é a concepção de que a objetividade "percebida" não é uma objetividade física, independente da consciência. Resulta daí uma expansão do conceito de objetividade. Uma vez que ser objetivo, do ponto de vista fenomenológico, significa manifestar fenomenologicamente como objetivo, não há razão para se prender ao preconceito de considerar que objetividades devem ter um aspecto coisal e concreto. Nota-se isso em famoso texto de Köhler, de 1944, "Fato e valor", onde ele defende que o valor, embora seja excluído das ciências naturais, as quais querem explicar tudo em termos de fatos neutros, não é, por isso, fenomenologicamente subjetivo. Pelo contrário, "fenomenologicamente, o valor está localizado em objetos e ocorrências" (Köhler, 1944/1978b, p. 116). O valor é dado na experiência direta como algo tão objetivo quanto uma cadeira percebida. Afirmar que o valor é fenomenologicamente subjetivo seria falsificar "nossos dados primários de observação" (1944/1978b, p. 116), seria recusar a evidência. Como exemplo, Köhler afirma que, em uma melodia, pode-se notar "lenta inquietação ou força tranquila”. (1944/1978b, p. 116). Essa posição não espanta e é até mesmo esperada dado o que foi apresentado até aqui. Tudo o que aparece diretamente como objetivo não é, em caso algum, nada de físico. Assim sendo, não há porque considerar que o que é o objetivo deve ter uma aparência física ou uma consistência concreta e sensível.
O mundo da vida cotidiana e o sujeito que vive a vida cotidiana fazem parte de um mesmo sistema e ambos só existem, por assim dizer, como correlatos (1929/1968, p. 23). Sem o sujeito não há o mundo da experiência objetiva direta (mundo cotidiano), e sem este, não há vida subjetiva possível. Mas o que dizer da relação entre o mundo da física e o mundo cotidiano? A resposta de Köhler é que o segundo depende ontologicamente do primeiro, ao passo que o primeiro depende epistemologicamente do segundo (1929/1968; p. 24, 1938, p. 145). O mundo cotidiano é condição de possibilidade do conhecimento do mundo da física e das demais ciências (Köhler, 1929/1968, p. 20, 21). Essa posição é mantida por Köhler em 1960, seis anos antes de sua morte: o mundo fenomenológico é de onde se retira todo material para a dita construção do mundo físico (1960/1978a, p. 135). Do ponto de vista epistemológico, o mundo físico é apenas suposto. Mas, ao contrário de outros fenomenólogos, como Husserl (1913/1950), ou filósofos que empregaram o método fenomenológico (Heidegger; 1927/2012, p. 103-111), Köhler não só aceita a tese de um mundo exterior e independente, como entende que a tarefa do cientista é conhecê-lo. Mas, para isso, como já salientamos, é necessária a experiência imediata ou fenomenológica, a qual precede não só logicamente quanto temporalmente a experiência mediata, pela qual temos acesso inferencial ao mundo físico. Tanto na história do indivíduo quanto na história da humanidade, o conhecimento do mundo fenomenológico precede o conhecimento do mundo físico e de suas propriedades. (Köhler, 1929/1968, p. 10). Mas é preciso enfatizar que a experiência fenomenológica não possui apenas primazia cronológica, mas também lógica e epistemológica, pois é a condição de possibilidade da experiência mediata. Mas se o mundo cotidiano tem prioridade epistemológica, isso não significa prioridade ontológica. O mundo físico não é dependente ontologicamente do sujeito, já que toda experiência é geneticamente subjetiva, ou seja, é resultado de processos cerebrais.

\section{Apoio}

Está pesquisa teve o apoio da FAPESP.

\section{Referências}

Araújo, S. d. F. (2013). O Manifesto dos filósofos alemães contra a psicologia experimental: introdução, tradução e comentários. Estudos e Pesquisas em Psicologia, 13(1), 298-311.

Aristotele. (2009). Metafisica (G. Reale, Trad.). Milano: Bompiani. (Originalmente publicado no séc. IX a.C)

Brentano, F. C. (1874). Psychologie vom empirischen Standpunkt. Leipzig: Verlag von Duncker \& Humblot. 
Descartes, R. (1973). Meditações. In V. Civita (Ed.), Descartes (Vol. XV). São Paulo: Abril Cultural (Originalmente publicado em 1641).

Engelmann, Arno. (2002). A psicologia da gestalt e a ciência empírica contemporânea. Psicologia: Teoria e Pesquisa, 18(1), 1-16.

Ehrenfels, C. (1890). Über Gestaltqualitäten. Leipzig: Reisland.

Hatfield, G. (2003). Routledge philosophy guidebook to Descartes and the meditations. London; New York: Routledge.

Heidegger, M. (2012). Ser e tempo: edição em alemão e português (F. Castilho, Trad.). Campinas: Editora da Unicamp (Originalmente publicado em 1927)

Husserl, Edmund. (1950). Ideen zu einer reinen Phänomenologie und phänomenologischen Philosophie. Buch 1, Allgemeine Einführung in die reine Phänomenologie. Den Haag: Nijhoff (Originalmente publicado em 1913)

Husserl, Edmund. (1968). Logische Untersuchungen. Erster Band: Prolegomena zur reinen Logik. Haag: Martinus Nijhoff (Originalmente publicado em 1900).

Katz, D. (1911). Die Erscheinungsweisen der Farben und ihre Beeinflussung durch die individuelle Erfahrung. Leipzig: J.A. Barth.

Katz, D. (1950). Gestalt psychology: its nature and significance. New York: Ronald.

Koffka, K. (1975). Princípios de psicologia da Gestalt. SãoPaulo: Cultrix (Original publicado em 1935).

Köhler, W. (1961). Gestalt psychology Today. In M. Henle (Ed.), Documents of Gestalt psychology (p. 1-15). Berkeley: University of California Press.

Köhler, W. (1968). Psicologia da Gestalt. Belo Horizonte: Itatiaia (Original publicado em 1929).

Köhler, W. (1970). Gestalt psychology: an introduction to new concepts in modern psychology. New York: Liveright (Original publicado em 1929).

Köhler, W. (1971b). A Task for Philosophers. In M. Henle (Org.), The selected papers of Wolfgang Köhler (p. 83-107). New York: Liveright (Original publicado em 1966).

Köhler, W. (1978a). O problema mente-corpo. In A. Engelmann (Org.), Wolfgang Köhler (p. 129-147). São Paulo: Ática (Original publicado em 1960)

Köhler, W. (1978b). Valor e Fato. In A. Engelmann (Org.), Wolfgang Köhler (p. 109-128) São Paulo: Ática (Original publicado em 1944).

Locke, J. (1975). An essay concerning human understanding. Oxford: Clarendon Press. (Originalmente publicado em 1689)

McCann, E. (2006). Locke's philosophy of body. In V. C. Chappell (Ed.), The Cambridge companion to Locke (p. 56-88). Cambridge: Cambridge University Press.

Rockmore, T. (2011). Kant and phenomenology. Chicago: University of Chicago Press.
Smith, B. (1994). Austrian philosophy: the legacy of Franz Brentano. Chicago: Open Court.

Spillmann, L., \& Ehrenstein, W. H. (2003). Gestalt factors in the visual neurosciences? In J. S. Werner \& L. M. Chalupa (Eds.), The visual neurosciences (p. 1573-1589). Cambridge, MA: MIT Press.

Sávio Passafaro Peres - Possui Graduação, Mestrado e Doutorado em Psicologia pela Universidade de São Paulo. Atualmente é Pós-Doutorando em Filosofia pela Pontifícia Universidade Católica de São Paulo (PUC-SP). É professor visitante de filosofia da Universidade Camilo Castelo Branco, Membro do GT de Fenomenologia da Associação Nacional de Pós-Graduação em Filosofia (ANPOF) e do GT de História da Psicologia da Associação Nacional de Pesquisa e Pós-Graduação em Psicologia (ANPEPP). E-mail: savioperes@yahoo.com.br

Recebido em 06.05.2013 Primeira Decisão Editorial em 02.02.2014 Aceito em 25.02.2014 